\title{
Effect of Kegel Exercise on Improving Manifestations of Uterine Prolapse among Pre menopausal Women
}

\author{
Shaimaa Gamal Ramadan Hassan ${ }^{1}$, Manal Farouk Moustafa ${ }^{2}$, Hoda Abd Elazim Mohamed ${ }^{3}$, Ahmed Samier Abd El-Malek \\ (1) Clinical instructor- Technical Institute of Nursing - Minia University \\ (2) Professor of Obstetric \&Gynecological Nursing \& Reproductive Health -Faculty of Nursing- Assiut University. \\ (3) Professor of Women Health and Obstetrics Nursing- Faculty of Nursing - Minia University. \\ (4) Professor of obstetrics \& Gynecology- Faculty of Medicine - Minia University.
}

Corresponding Author: Shaimaa Gamal Ramadan Hassan

\begin{abstract}
Background: The symptoms of uterine prolapse can be extremely debilitating \& have an appreciable impact on quality of life (Streicher. L , 2013). Pelvic floor exercises can improve the symptoms in mild and moderate cases and sometimes prevent the pelvic organs from slipping down further (Hassan \& Mahmoud, 2017). Aim of the study: To evaluate the effect of Kegel exercise on improving manifestations of uterine prolapse among pre-menopausal women. Research design: Quasi-experimental design was adopted to conduct this study. Setting: The study was conducted at gynecological outpatient clinics at Minia University Hospital for Obstetric \& Pediatric and El - Minia General Hospital. Subjects: A Purposive sample composed of 102 pre-menopausal women was recruited for the current study and divided equally by using simple random sample into study \&control groups. Tools of data collection: Three tools were used as following: 1- A structured interviewing questionnaire, 2- Pelvic Organ Prolapse symptoms score (POP-ss), 3- Follow up evaluation sheet (diary record). Results: The current study reveals; that there were a strong negative correlation between uterine prolapse symptoms and women compliance to performance of Kegel exercise after 6 weeks and 3 months of the intervention with statistical significant differences at $(\mathrm{P}$ value $\leq$ 0.046 and $\mathrm{P}$ value $\leq 0.003$ ). Conclusion \& Recommendations: Implementation of Kegel exercises had a highly significance effectiveness' in improving manifestations of uterine prolapse among pre-menopasual women. In addition applying an educational program about Kegel exercises for women was recommended.
\end{abstract}

Keywords: Kegel exercises, Manifestations of prolapse, Uterine prolapse.

\section{Introduction}

Uterine prolapse is a health concern affecting millions of women worldwide. When it defined by symptoms has prevalence of 3-6\% and up to $50 \%$ when based upon vaginal examination (Barber \& Maher, 2013). The mean prevalence in low-income countries is $19.7 \%$ (range $3.4 \%$ 56.4\%) (Jokhio, et al., 2013) .However; A population based study $(n=2070)$ by UNFPA in Nepal found a prevalence of uterine prolapse were $10 \%$ included women had 'something coming down in the vagina' (Walker \& Gunasekera, 2011). More recent studies from Ethiopia (Belayneh, et al., 2019 and Ballard, et al., 2016) and Tanzania (Masenga, et al, 2018) showed prevalence of UP based on symptoms included up to $64.6 \%$ based on clinical examination.

It defined as the descent of uterus and vaginal walls through vaginal canal. Uterus, move downwards due to anatomical or functional deformities of the tissues and ligaments that support the uterus (Memon \& Handa, 2012).

Pre-menopause is an even a greater risk factor for uterine prolapse; it associated with profound reproductive and hormonal changes (Binjwala, et al, 2014). Also, additional risk factors associated with UP have been shown as; Birth weights, MOD (Mode of Delivery) and length of the second stage of labor (Walker \& Gunasekera, 2011).

The symptoms of uterine prolapse depend on the degree of the prolapse. More significant uterine prolapse may cause pelvic pain or pressure. It may also interfere with sexual function (Hagen \& Stark, 2011).

In a minimal prolapse, women may not develop any bothersome symptoms prolapse may be asymptomatic and require no treatment. Some women with a more advanced condition prefer observation to other treatments, but should be examined regularly (Buckler, 2017).

According to Priyanka, et al, (2010), the main symptom of uterine prolapse is seeing or feeling of bulging in the vagina. The presentation of symptom may be varying among individuals and it depends on the severity of prolapse. The association between childbearing and Uterine Prolapse (UP) giving rise to symptoms of pelvic floor dysfunction (PFD) (Elenskaia, et al, 2013).

Measures used for reducing the impact of uterine prolapse symptoms includes ; training of Kegel exercises and life style changes. These exercises strengthens levator ani muscle through muscular hypertrophy and stronger levator ani muscle improves support and reduces the burden imposed on the ligament (Berzuk \& Shay, 2015) .

During the transition phase to menopause, the maternity nurse plays an important role in prevention of prolapse through giving the woman health education about diet, exercise and follow- up and its importance for early detection of any genital abnormalities (Vorvick, 2011).

\section{Significance of the study}

In Egypt and Arab countries half of the women had duration of UP more than 5 years and $6 \%$ of women had UP for more than 20 years. Overall more than $60 \%$ of women reported symptoms (Fitchett, et al, 2015).

Menopause is a consequence of age; there is a straight association between menopause and an increased risk for UP (Weintraub, et al, 2020 and Sze, et al, 2012). The hormonal changes in menopause cause a drop in the systemic estrogen concentrations, contributes to alterations in the 
composition and strength of collagen. This particular hormone helps keep pelvic muscles strong. Without it, premenopausal women at a higher risk of developing uterine prolapse (Alcalay, et al, 2015).

Conservative treatments for uterine prolapse during menopause for pre- menopausal women include; Pelvic Floor Muscle Training (PFMT), which used in cases of mild to moderate prolapse \& may help to relieve symptoms (Bordman, et al., 2014). In addition, Kegel Exercise or PFMT is safe, effective and an inexpensive therapy. This highlights the need for using preventive measure includes Kegel exercise for the improvement of signs and symptoms of uterine prolapse; (Golmakani, et al., 2012, Binjwala, et al., 2015 \& Priyanka, et al., 2015).

\section{Aim of the study}

The present study was conducted to; evaluate the effect of Kegel exercise on improving manifestations of uterine prolapse among pre-menopausal women.

\section{Research hypothesis}

H1. Women who follow Kegel exercise training will have improvement in their manifestations of uterine prolapse than those who do not follow.

\section{Subjects and Methods}

Research design: Quasi-experimental research design (time series design) was utilized for the purpose of the current study.

Research Setting: The study was conducted at gynecological outpatient clinics at Minia University Hospital for Obstetrics \& Pediatric and El - Minia General Hospital. Both hospitals offer care services to all women who have gynecological problems \& living in Minia City districts and villages related to Minia Governorate.

\section{Subjects:}

Sample type: Purposive sample composed of 102 pre-menopausal women with $1^{\text {st }}, 2^{\text {nd }}$ degree uterine prolapse was recruited for the current study and divided equally by using simple random sample into study group $(n=51$ cases $) \&$ control group ( $n=51$ cases $)$ according to the following inclusion and exclusion criteria:

\section{Inclusion Criteria:}

- Age group ranged from 40-50 years.

- Educated women.

- Women who clinically diagnosed as uterine prolapse $\left(1^{\text {st }}\right.$ and $2^{\text {nd }}$ degree $)$.

- Multipara women.

\section{Exclusion criteria:}

- Women with reproductive tract infection \& urinary tract infection or any other gynecological complications.

- Women with $3^{\text {rd }} \& 4^{\text {th }}$ degree uterine prolapse.

Sample Size: The determination of the sample size was based upon the flow number 340 pre-menopausal women (The attendants' rate of pre-menopausal women -in each clinic for both hospitals was estimated during 2017 before starting the study). Sample size was $102 \&$ it was calculated by using the Isaac, S. \& Michael, W.B. (2000) formula which is computed as $(\mathrm{N}=\mathrm{P} \times 30 / 100)$
Description:

$\mathrm{N}=$ Sample size

$\mathrm{P}=$ Uterine prolapse prevalence in target population $\mathrm{N}=340 \times 30 / 100=102$ patients.

Tools of Data Collection:

Three tools for data collection were used in the present study:

Tool I (pre-intervention):

A Structured interviewing questionnaire was developed by the investigator to collect data and divided in to three parts;

Part (1): Personal data of women such as; (Age, marital status, residence, level of education......, etc).

Part (2): Obstetrics \& gynecological history of women such as; (Gravidity, parity, mode of last deliveries......, etc).

Part (3): Medical history such as; (Medical diseases, problems resulting in increasing pressure in abdomen, problems associated with elimination......, etc).

\section{Tool II (pre/ post intervention):}

Pelvic Organ Prolapse - symptoms score (POP-ss) adopted from (Hagen, et al., 2004):

This tool used \& modified by the investigator to score the symptoms of uterine prolapse, it was a structured questionnaire included 7questions and modified into 10 questions. The total up the scores for $\mathrm{Q} 1-\mathrm{Q} 10$ range $0-40$ was calculated by summing the ten individual symptom responses. The best possible score would be 0 - meaning haven't been complaint of these symptoms at all, the moderate score would be 10- $<40$ meaning that some of these symptoms bother woman all of the time, and the worst or severe would be 40- meaning that all of these symptoms bother woman all of the time.

The investigators used this tool three times through the present study, the first time before intervention, the second time after 6 weeks from intervention and third one after 3 months from the intervention to evaluate the program effects after intervention as prolapse symptoms improved by compare the baseline symptoms scores before intervention with the symptoms after intervention.

\section{Tool III ( pre/ post ):}

Follow up evaluation sheet (dairy record) adopted from (Priyanka. et al, 2011 \& Egyptian Journal of Hospital Medicine, 2017):

This tool was modified by the investigator in the form of dairy record to assess the frequency \& duration of performance of Kegel exercise (compliance of women). Diary record was given to women in the study group to record their compliance of Kegel exercises at their homes. The investigator instructed them to document their compliance by put a circle for documenting frequencies of performing Kegel exercises through a day, time of relaxation / contraction and number of relaxation / contraction. The investigator followed up the study group after using this tool by them 3 times through the current study (The $1^{\text {st }}$ time after 1 month, the $2^{\text {nd }}$ time after 6 weeks and $3^{\text {rd }}$ time after three months from the intervention).

\section{Supportive material:}

It was designed by the investigator in form of handout (booklet) after revising extensive relevant literature 
review such as (Abrams, et al., 2012) \& (Boyle, et al., 2014). It was written in a simple Arabic language $\&$ it was developed and supported with photos and illustrations to help the woman understanding the content of the booklet. This handout consisted of description about anatomy of female reproductive system, complete description about uterine prolapse, and complete description of Kegel exercises.

Validity \& Reliability: The questionnaire was piloted on panel of 5 experts of Obstetrics and gynecological staff, and nursing professors who reviewed the instruments for clarity, relevance, comprehensiveness, understanding, applicability and easiness. Alpha Cronbach's test was used to check the stability of the internal consistency of instrument.

\section{Pilot study}

It was carried out on $10 \%$ of the total study sample (10 pre-menopausal women). It was conducted to evaluate the applicability and clarity of the tools, assessment of feasibility of fieldwork and to detect any possible obstacles that might face the investigator and interfere with data collection. Necessary modifications were done based on contents for more simplicity and clarity. The subjects were not included to the actual sample.

\section{Fieldwork:}

After the conduction of the pilot study as well as the actual study, an official permission and consent was obtained from the dean of the Faculty of Nursing, as well as the Director of Minia University Hospital for Obstetric and Pediatric \& El- Minia General Hospital \& the head of internal medicine department at both hospitals. All women aged between 40-50 yrs who clinically diagnosed as uterine prolapse $\left(1^{\text {st }}\right.$ and $2^{\text {nd }}$ degree $)$ by the gynecologist was included in this study. Then the investigator was started to collect data through four phases included: 1) Interviewing; 2) Implementation; 3) Follow up and 4) Evaluation phases.

\section{(Interviewing phase):}

At the beginning of this phase, the investigator visited data collection site from 9:00 Am to 1:00 Pm, for 2 days per week (Sunday and Tuesday). This phase was applied to control and study groups of pre- menopausal women.

The investigator held the first interview with each woman in the out patient gynecological clinics during examination by the doctor or after examination before leaving the clinics introduced her-self, Oral consent for participation in the study was obtained from selected pre-menopausal women for ethical issues \& scheduled times and frequency of sessions and follow up, mobile phone numbers were saved to all selected women to assure adherence to the intervention.

The investigator collected data using the first, second and third tools from control and study group. The investigator asked pre- menopausal woman questions about their sociodemographic characteristics such as (age, marital status, ....ect), obstetrics and gynecological history included (Gravidity, parity, ....ect), and medical history included (Medical complaints, problems resulting in increasing pressure in abdomen, .....ect).

The structured interviewing sheet was filled by the investigator and she used the second tool (Pelvic organ prolapse - symptoms score (POP-ss) for assessing prolapse symptoms. Each interview took about 15 to 20 minutes for each pre- menopausal woman to be completed.

\section{(Implementation phase):}

The investigator conducted the educational sessions about Kegel exercise for pre- menopausal woman in the study group. The total number of Kegel exercise training sessions was 1 - 2 sessions (2 days/week) through 4 weeks varied according to understanding of each participant. Duration for each session was ranged from 20 to 35 minutes \& it was conducted after organization with gynecologist in the outpatient clinics before the women left the clinic.

The first session took about 20 minutes and at the beginning of this session, the investigator introduces her-self, explained the objective of the research; gave them an educational booklet about Kegel exercises and then illustrated the content of the booklet; through gave the women simple information about anatomy of the female reproductive system, anatomy of the female pelvis, and anatomy of pelvic floor muscles.

The second session (practical session) took about 25 minutes; the investigator gave the women a detailed explanation about Kegel exercise and helps the women to identify the correct muscle for Kegel training individualized by asked them to lie down on the bed in supine position with knees bent and focus on the perineal area and completely relax the perineal area. Then two fingers were put inside the vagina, and the woman was asked to contract her pelvic floor muscles just like when she holds the urine and she had to try to pull the investigator's finger upward and inward.

After identifying these muscles, the pre-menopausal women in the study group were asked to contract the pelvic floor muscles during examination of the vagina, and then after ensuring proper contraction of the muscle, they were asked to do these exercises twice daily, each time 15-20 times depending on their ability to contract their pelvic floor muscles for 5-10 s and relax for 5-10 s and repeating this exercise for 20 times (for $5 \mathrm{~min}$ ). After $2 \mathrm{~min}$ of rest, they again had to perform this exercise for 3 times of $5 \mathrm{~min}$. so that a total of 20 minutes of exercise is performed at each time.

However, the investigator asked them to repeat exercise 1 to 2 times per day from the first day until one month, then (2-3 $\mathrm{min})$ and repeated 1 to 2 times from the first day after one month post - intervention until two months and then (3-5 $\mathrm{min}$ ) and repeated 2 to 4 times from the first day after two months post - intervention until three months.

The investigator used tool III (follow up sheet) which includes the duration of exercise per day, performing exercise according to training program and instructed them for recording their compliance at home. It was taken from them at the end every 4 weeks to ensure women's compliance.

However, control group of pre-menopausal women received routinely care from the hospital at out- patient gynecological clinics.

\section{(Follow up phase)}

The investigator used her telephone number for calling with women in the study group every 2 weeks to find out if they were regularly performing the exercises and have any other problems facing them to determine degree of her compliance with pelvic floor muscle exercises at home and checked women progress. However, the investigator calling women in the control group to ensure routine hospital care.

\section{(Evaluation phase)}

Evaluation phase was done at pre intervention as a base data and after 6 weeks \& 3 months at the outpatient 
Minia Scientific Nursing Journal (Print - ISSN 2537-012X) (Online - ISSN 2785-9797) Vol. (8) No. (1) December 2020

gynecological clinic. The investigator interviewed prethe progress of uterine prolapse symptoms by using the second menopausal women in the study and control groups to assess tool (Pelvic organ prolapse - symptoms score (POP-ss).

\section{Results}

Table (1): Distribution of pre-menopausal women regarding to their socio-demographic characteristics $(\mathrm{n}=102)$

\begin{tabular}{|c|c|c|c|c|c|c|}
\hline \multirow[t]{2}{*}{ Items } & \multicolumn{2}{|c|}{ Study $(n=51)$} & \multicolumn{2}{|c|}{ Control $(n=51)$} & \multirow[t]{2}{*}{ Sig. test } & \multirow[t]{2}{*}{ P-value } \\
\hline & No. & $\%$ & No. & $\%$ & & \\
\hline \multicolumn{7}{|l|}{ Age / Years } \\
\hline - $40->45$ & 28 & 54.9 & 24 & 47.1 & \multirow{3}{*}{$t=0.760$} & \multirow{3}{*}{$\begin{array}{l}0.449 \\
\text { NS }\end{array}$} \\
\hline $45-50$ & 23 & 45.1 & 27 & 52.9 & & \\
\hline Mean \pm SD & \multicolumn{2}{|c|}{$44.8 \pm 3.39$} & \multicolumn{2}{|c|}{$45.3 \pm 3.38$} & & \\
\hline \multicolumn{7}{|l|}{ Marital Status } \\
\hline Married & 74 & 80.4 & 38 & 74.5 & \multirow{3}{*}{$\chi^{2}=1.25$} & \multirow{3}{*}{$\begin{array}{l}0.533 \\
\text { NS }\end{array}$} \\
\hline Divorced & 4 & 7.8 & 3 & 5.9 & & \\
\hline Widow & 6 & 11.8 & 10 & 19.6 & & \\
\hline \multicolumn{7}{|l|}{ Residence } \\
\hline Rural & 37 & 72.5 & 36 & 70.6 & \multirow{2}{*}{$\begin{array}{l}\chi^{2}= \\
0.048\end{array}$} & \multirow{2}{*}{$\begin{array}{l}0.826 \\
\text { NS }\end{array}$} \\
\hline Urban & 14 & 27.5 & 15 & 29.4 & & \\
\hline \multicolumn{7}{|l|}{ Level of Education } \\
\hline Read \& write & 20 & 39.2 & 21 & 41.2 & \multirow{4}{*}{$\chi^{2}=1.55$} & \multirow{4}{*}{$\begin{array}{l}0.670 \\
\text { NS }\end{array}$} \\
\hline Basic education & 18 & 35.3 & 20 & 39.2 & & \\
\hline Secondary & 8 & 15.7 & 4 & 7.8 & & \\
\hline University & 5 & 9.8 & 6 & 11.8 & & \\
\hline \multicolumn{7}{|l|}{ Occupation } \\
\hline House wife & 39 & 76.5 & 35 & 68.5 & \multirow{2}{*}{$\begin{array}{l}\chi^{2}= \\
0.788\end{array}$} & \multirow{2}{*}{$\begin{array}{l}0.375 \\
\text { NS }\end{array}$} \\
\hline Work & 12 & 23.5 & 16 & 31.4 & & \\
\hline
\end{tabular}

Table (1): There was no statistical significance difference between the two groups regarding to sociodemographics characteristics

Table (2): Distribution of Pre-Menopausal Women Regarding to Uterine Prolapse- symptoms Pre and Post Intervention $(\mathbf{n}=\mathbf{1 0 2})$

\begin{tabular}{|c|c|c|c|c|}
\hline \multirow[t]{2}{*}{ POP-ss } & Study $(n=51)$ & Control $(n=51)$ & \multirow[t]{2}{*}{ t test } & \multirow[t]{2}{*}{$P$-value } \\
\hline & Mean \pm SD & Mean \pm SD & & \\
\hline Pre-Intervention & $26.0 \pm 7.37$ & $26.5 \pm 7.7$ & 0.353 & 0.725 \\
\hline Post 6 weeks & $19.5 \pm 6.02$ & $26.5 \pm 7.7$ & 5.08 & $0.000 * *$ \\
\hline Post 3 months & $15.4 \pm 5.37$ & $27.0 \pm 7.5$ & 8.97 & $0.000 * *$ \\
\hline
\end{tabular}

Table (2) Shows that there were a highly statistical significant difference between both groups (study and control) at (P.value $\leq 0.000)$ regarding to uterine prolapse- symptoms post- intervention compared with no statistical significant difference at $(\mathrm{P}$. value $=$ $0.725)$ pre- intervention respectively

Table (3): Distribution of pre-menopausal women regarding to their degree of uterine prolapse symptoms (n=102)

\begin{tabular}{|c|c|c|c|c|c|c|c|c|c|c|c|c|}
\hline \multirow{3}{*}{$\begin{array}{l}\text { Degree of uterine } \\
\text { prolapse symptoms }\end{array}$} & \multicolumn{4}{|c|}{ Pre Intervention } & \multicolumn{4}{|c|}{ Post 6 weeks } & \multicolumn{4}{|c|}{ Post 3 months } \\
\hline & \multicolumn{2}{|c|}{ Study $(n=51)$} & \multicolumn{2}{|c|}{ Control $(n=51)$} & \multicolumn{2}{|c|}{ Study $(n=51)$} & \multicolumn{2}{|c|}{ Control $(n=51)$} & \multicolumn{2}{|c|}{ Study (n=51) } & \multicolumn{2}{|c|}{ Control $(n=51)$} \\
\hline & No. & $\%$ & No. & $\%$ & No. & $\%$ & No. & $\%$ & No. & $\%$ & No. & $\%$ \\
\hline Mild & 10 & 19.6 & 12 & 23.5 & 18 & 35.3 & 12 & 23.5 & 38 & 74.5 & 12 & 23.5 \\
\hline Moderate & 21 & 41.2 & 20 & 39.2 & 30 & 58.8 & 20 & 39.2 & 12 & 23.5 & 15 & 29.4 \\
\hline Severe & 20 & 39.2 & 19 & 37.5 & 3 & 5.9 & 19 & 37.3 & 1 & 2 & 24 & 47.1 \\
\hline $\begin{array}{l}\text { Fisher's exact (P - } \\
\text { value) }\end{array}$ & & & $.096)$ & & & 15.4 & $002 * *$ & & & & $000^{* *}$ & \\
\hline
\end{tabular}

Table (3): It reveals that there was a highly statistical significant difference between study and control groups regarding to degree of uterine prolapse symptoms post- intervention at $(\mathrm{P}$ value $\leq 0.002)$ after 6 weeks and at $(\mathrm{P}$ value $\leq 0.000)$ after 3 months compared with no statistical significance difference at $(\mathrm{P}$ value $=0.096)$ pre- intervention respectively

Table (4): Relation between socio-demographic characteristics with uterine prolapse degree of symptoms among premenopausal women

\begin{tabular}{|c|c|c|c|c|c|c|}
\hline \multirow{4}{*}{ Socio demographic characteristics } & \multicolumn{6}{|c|}{ Degree of Symptoms } \\
\hline & \multicolumn{2}{|c|}{ Mild } & \multicolumn{2}{|c|}{ Moderate } & \multicolumn{2}{|c|}{ Severe } \\
\hline & Study & Control & Study & Control & Study & Control \\
\hline & No. & No. & No. & No. & No. & No. \\
\hline \multicolumn{7}{|l|}{ Age } \\
\hline $40->45$ & 10 & 9 & 10 & 11 & 8 & 10 \\
\hline $45-50$ & 0 & 3 & 12 & 8 & 11 & 1 \\
\hline
\end{tabular}


Minia Scientific Nursing Journal (Print - ISSN 2537-012X) (Online - ISSN 2785-9797) Vol. (8) No. (1) December 2020

\begin{tabular}{|c|c|c|c|c|c|c|}
\hline \multirow{4}{*}{ Socio demographic characteristics } & \multicolumn{6}{|c|}{ Degree of Symptoms } \\
\hline & \multicolumn{2}{|c|}{ Mild } & \multicolumn{2}{|c|}{ Moderate } & \multicolumn{2}{|c|}{ Severe } \\
\hline & Study & Control & Study & Control & Study & Control \\
\hline & No. & No. & No. & No. & No. & No. \\
\hline P value & \multicolumn{6}{|c|}{$17.93\left(0.000^{* *}\right)$} \\
\hline \multicolumn{7}{|l|}{ Educational level } \\
\hline Read \& write & 2 & 4 & 4 & 8 & 14 & 9 \\
\hline Basic education & 3 & 7 & 10 & 3 & 5 & 10 \\
\hline Secondary & 3 & 1 & 5 & 3 & 0 & 0 \\
\hline University & 2 & 0 & 3 & 5 & 0 & 1 \\
\hline P value & \multicolumn{6}{|c|}{$19.25\left(0.004^{* *}\right)$} \\
\hline \multicolumn{7}{|l|}{ Occupation } \\
\hline House wife & 4 & 11 & 16 & 8 & 17 & 16 \\
\hline Work & 6 & 1 & 6 & 11 & 2 & 4 \\
\hline P value & \multicolumn{6}{|c|}{$7.14(0.028 *)$} \\
\hline
\end{tabular}

Table (4): It illustrates the relationship between sociodemographics characteristics with uterine prolapse symptoms. It was noticed that there was a highly statistically significant relation between the pre-menopausal women's uterine prolapse symptoms with their age and educational status at $(\mathrm{P}$ value $\leq 0.000)$ and statistically significant with their occupation at $(\mathrm{P}$ value $\leq 0.028)$.

Table (5): Relation between Problems resulting in increasing pressure in abdomen with uterine prolapse degree of symptoms among pre-menopausal women

\begin{tabular}{|c|c|c|c|c|c|c|c|}
\hline & \multicolumn{6}{|c|}{ Problems resulting in increasing pressure in abdomen } \\
\hline & & \multicolumn{2}{|c|}{ Chronic Cough } & \multicolumn{2}{|c|}{ Constipation } & \multicolumn{2}{|c|}{ Obesity } \\
\hline & & Study & Control & Study & Control & Study & Control \\
\hline & & No. & No. & No. & No. & No. & No. \\
\hline \multicolumn{8}{|c|}{ Symptoms } \\
\hline & Mild & 5 & 5 & 4 & 4 & 1 & 1 \\
\hline$\bullet$ & Moderate & 10 & 10 & 7 & 7 & 4 & 4 \\
\hline$\bullet$ & Severe & 2 & 2 & 13 & 13 & 5 & 5 \\
\hline & & \multicolumn{6}{|c|}{$16.9(0.024 *)$} \\
\hline
\end{tabular}

Table (5): This table illustrates the relation between problems resulting in increasing pressure in abdomen with uterine prolapse symptoms. It was observed that there was statistically significant relation between problems resulting in increasing pressure in abdomen with uterine prolapse degree of symptoms at ( $\mathrm{P}$ value $\leq 0.024)$ respectively

Table (6): Relation between uterine prolapse degree of symptoms with gravidity and parity among pre-menopausal women

\begin{tabular}{|c|c|c|c|c|c|c|}
\hline \multirow{4}{*}{ Items } & \multicolumn{6}{|c|}{ Uterine Prolapse degree of Symptoms } \\
\hline & \multicolumn{2}{|c|}{ Mild } & \multicolumn{2}{|c|}{ Moderate } & \multicolumn{2}{|c|}{ Severe } \\
\hline & Study & Control & Study & Control & Study & Control \\
\hline & No. & No. & No. & No. & No. & No. \\
\hline \multicolumn{7}{|c|}{ Gravidity } \\
\hline $1-3$ & 10 & 9 & 10 & 6 & 12 & 10 \\
\hline $4-5$ & 0 & 3 & 7 & 10 & 4 & 1 \\
\hline More than 5 & 0 & 0 & 5 & 3 & 3 & 9 \\
\hline P value & \multicolumn{6}{|c|}{$20.5(0.001 * *)$} \\
\hline \multicolumn{7}{|l|}{ Parity } \\
\hline None & 0 & 0 & 1 & 3 & 1 & 0 \\
\hline $1-3$ & 10 & 9 & 9 & 3 & 13 & 10 \\
\hline $4-5$ & 0 & 3 & 7 & 10 & 2 & 1 \\
\hline \multirow[t]{2}{*}{ More than 5} & 0 & 0 & 5 & 3 & 3 & 9 \\
\hline & \multicolumn{6}{|c|}{$30.6\left(0.001^{* *}\right)$} \\
\hline
\end{tabular}

Table (6): This table shows the relation between uterine prolapse degree of symptoms with gravidity and parity. It was, observed that there was a highly statistical significant relation between uterine prolapse degree of symptoms with gravidity and parity at $(\mathrm{P}$ value $\leq 0.001)$.

\section{Discussion}

The aim of this study was to assess the effect of Kegel's exercises on Improving Manifestations of Uterine Prolapse among Pre- menopausal Women. Findings of this study discussed to accept the research hypotheses; Women who follow Kegel exercise training will have improvement in manifestations of uterine prolapse than those who do not follow.
Regarding to the sociodemographics characteristics the current study findings reveals that the majority of premenopausal women among study group were married and nearly three-quarters between control and study groups were rural respectively.

This finding agreed with those of Bruno, et al., (2012) who studied randomized controlled trial on Efficacy of pelvic floor muscle training for treating pelvic organ 
prolapse in women, the rural and married women who had POP their age was more than 40 years. Also, Jokhio, et al (2020) who studied population based study on prevalence of pelvic organ prolapse in women, associated factors and impact on quality of life in rural Pakistan added that the incidence of prolapse affected by age was $25 \%$ of cases with age $36-40$ years but the most common age was $40-60$ years old $60 \%$. In relation to education levels in the present study, it was found that the largest percentages of study and control groups respectively were read and write. However, the lowest percentage of study and control groups respectively had Bachelor degree. Concerning occupation, the finding represented that the highest percentage among study and control groups were housewife between both groups were read and write. These findings disagreed with Hassan, Osman and Fayez (2015) who studied prevalence, risk factors and severity of symptoms of pelvic organ prolapse among Emirati women and approved that $98 \%$ of women in their study were educated and workable.

Furthermore, as regards to uterine Prolapse Symptoms, the current study findings displayed that, there were statistical significant differences between both groups regarding to improvement of prolapse staging post intervention after 3 months at ( $\mathrm{P}$ value $\leq 0.043$ ) respectively, which accepted the first research hypothesis which is women who follow Kegel's exercises will show less signs and symptoms than before.

In accordance with this finding Priyanka, et.al, (2015) who studied A pre-experimental study to assess the effectiveness of nursing intervention package on management of pelvic organ prolapse; reported that, the intensity of symptoms reduced to 1.3 to 0.7 after 4 months of intervention, also the total mean score decreased to 19.70 to 11.2 at 6 week and 6.22 at 4 months to show the effectiveness of Kegel's exercise on managing POP.

The findings of this research regarding uterine prolapse symptoms agreed with study done by Subhagan (2010), who applied educational program for 3 months about POP for women and proved that; women's knowledge, symptoms, and quality-of- life significantly improved in 3 months. While these findings disagreed with study done by Stüpp, et al., (2011) published randomized controlled trial who studied the Kegel's exercises on POP. Results showed that, there was no difference between the training group and control group regarding to treatment of pelvic organ prolapse. Also, the findings of this study disagreed with McClurg, et al., (2014) who examined the combination of PFMT with surgery or insertion of vaginal pessary. The study founded that application of PFME only not improve POP symptoms. Moreover, McClurg, et al., (2014) suggested that, pelvic floor exercises help to improve a mild prolapse and related symptoms. Pelvic floor muscle training resulted in significant anatomic improvement of anterior and posterior vaginal wall prolapse and better muscle strength.

Regarding compliance to Performance of Kegel Exercises, the current study results displayed that nearly two third were moderate compliance compared with the relation between women compliance to performance of Kegel Exercise with uterine prolapse symptoms after 1 and 3 months

These findings reflected that the adherence to performing exercises daily help increase it effect and may make it on time is usual and increase women self-efficacy to perform which increase PFM strength.
This study findings was in the same line with a recent randomized controlled trial to Intensive supervised versus unsupervised pelvic floor muscle training for the treatment of stress urinary incontinence; a randomized comparative trial by Felicissimo, (2010) found that commitment to PFMT was as effective for women with POP and increases their compliance and exercise adherence, which lead to successful effect.

Moreover, the current study findings revealed that there was a relationship between socio-demographic characteristics with uterine prolapse symptoms. It was noticed that there was a highly statistically significant relation between the pre-menopausal women's uterine prolapse symptoms with their age and educational status at $(\mathrm{P}$ value $\leq 0.000)$ and statistically significant with their occupation at $(\mathrm{P}$ value $\leq 0.028$ ).

These findings reflected that the pre-menopausal, educated and workable women may had source of information about risk factors for uterine prolapse including vaginal childbirth, advancing age, more births and they tried to avoid these factors

In relation to this result, several epidemiological studies as Dumoulin, Hay-Smith (2010) who studied Pelvic floor muscle training versus no treatment, or inactive control treatments, for urinary incontinence in women; they have the similar finding when examined the association between uterine prolapse symptoms and stages and participant characteristics such as age, education, and parity.

These factors were theoretically hypothesized as significant confounders of POP this comparable between younger and older participant educated, non- educated.

Moreover, it was observed that there was statistically significant relation between problems resulting in increasing pressure in abdomen with uterine prolapse degree of symptoms. This may be regarded to that there is evidence that a vaginal delivery, and increased abdominal pressure significantly weakens and stretches the pelvic floor muscles and increase susceptibility to uterine prolapse.

These findings supported by Shrestha, et.al, (2014) who found in their study majority of respondents $(81.3 \%)$ increasing pressure on abdomen and carrying heavy loads as causes of uterine prolapse and increase its symptoms.

Moreover, it was, observed that there was a highly statistical significant relation between uterine prolapse degree of symptoms with gravidity and parity at ( $\mathrm{P}$ value $\leq 0.001)$. As over the last few years, there has been increasing interest in the role of levator ani-muscle injuries in the development of uterine prolapse; there was relation between levator ani defects and uterine prolapse; women with levator ani defects are at least twice as likely to show clinically significant uterine prolapse. Ani muscle strongly affected by women gravidity and parity. This result supported by Acharya, (2016) who studied Contributing Factors of Utero-vaginal Prolapse among Nepali Parous Women and Divya, et al. (2015) who studied Knowledge Regarding Utero -vaginal Prolapse among Women in Sree Balaji Medical College and Hospital who reported that uterine prolapse strongly affected by mode of delivery and parity with statistical significance differences.

\section{Conclusion \& Recommendations}

The current study findings concluded that Kegel exercise had been demonstrated to be effective in inducing significant improvement in manifestations of uterine prolapse among pre-menopausal women. 
In the light of the findings of the present study, the following recommendations are suggested by the investigator:

- $\quad$ Providing standardized plan of care based on Kegel exercises training for treatment of uterine prolapse that may have positive impact on women future health and their QOL.

- Applying an educational program about performance of Kegel exercise for women after labor (postpartum) to avoid complications such as uterine prolapse.

- Further researches are needed in a larger probability sample in different geographical areas in Egypt, especially rural areas to figure out the main aspects of these problems \& to implement PFMT (Kegel exercise) for women with uterine prolapse undergoing treatment

\section{Conclusion \& Recommendations}

The current study findings concluded that Kegel exercise had been demonstrated to be effective in inducing significant improvement in manifestations of uterine prolapse among pre-menopausal women.

In the light of the findings of the present study, the following recommendations are suggested by the investigator:

- Providing standardized plan of care based on Kegel exercises training for treatment of uterine prolapse that may have positive impact on women future health and their QOL.

- Applying an educational program about performance of Kegel exercise for women after labor (postpartum) to avoid complications such as uterine prolapse.

- Further researches are needed in a larger probability sample in different geographical areas in Egypt, especially rural areas to figure out the main aspects of these problems \& to implement PFMT (Kegel exercise) for women with uterine prolapse undergoing treatment.

\section{References}

(1) Acharya S. (2016): Contributing Factors of Utero-vaginal Prolapse among Nepali Parous Women. International Journal of Nursing Research and Practice; 3(2).

(2) Ballard .K, Ayenachew. F, Wright. J, Atnafu H (2016): Prevalence of obstetric fistula and symptomatic pelvic organ prolapse in rural Ethiopia. Int Urogynecol J. 27(7):1063-7.

(3) Barber, M.D., Maher, C. (2013): Epidemiology and outcome assessment of pelvic organ prolapse. Int Urogynecol J 24, 17831790. https://doi.org/10.1007/s00192-013-2169-9.

(4) Belayneh T, Gebeyehu A, Adefris M, Rortveit G, Awoke T (2019): Pelvic organ prolapse in Northwest Ethiopia: a populationbased study. Int Urogynecol J. 1-9.

(5) Berzuk K, Shay B (2015) .Effect of increasing awareness of pelvic floor muscle function on pelvic floor dysfunction: a randomized controlled trial. Int Urogynecology J 26 (6):837-844

(6) Binjwala S, Bhimsen D, Badri B, Bishnu C, Durga P, Sharad O, Max P, \& Alexandra K (2014 ): Knowledge on uterine prolapse among married women of reproductive age in Nepal. International Journal of Women's Health [Internet]. [Cited 2017Sep]; 6:771-9.

(7) Binjwala S, Sharad O, Bishnu C, Rajan P, Max P, \& Alexandra K.(2015): Uterine prolapse and its impact on quality of life in the Jhaukhel- Duwakot Health Demographic Surveillance Site, Bhaktapur, Nepal. Glob Health Action, 8: 28771.

(8) Bordman R, Telner D, Jackson B, Little D (2014): Step by-step approach to managing Pelvic Organ Prolapse. Canadian Family Physician; 53: 485-487. Available from: URL: http://www.ncbi.nlm.nih.gov.
(9) Buckler H, (2017) : The menopause transition endocrine changes and clinical symptoms. JBMS; 11(2):61-5.

(10) Divya, Hemavathy, Sathiyalatha S. (2015): Knowledge Regarding Utero -vaginal Prolapse among Women in Sree Balaji Medical College and Hospital, Chennai. Journal of Nursing and Health Science ; 4(1).

(11) Dumoulin C, Hay-Smith J. (2010): Pelvic floor muscle training versus no treatment, or inactive control treatments, for urinary incontinence in women. Cochrane Database Syst Rev Jan 20;(1): CD005654

(12) Elsayed, F., Ahmed, M., \& Gaheen, M. A. S. A. (2016): Knowledge and Practices of women regarding risk factors of uterine prolapse. IOSR Journal of Nursing and Health Science (IOSR-JNHS), 5(6), 60-7.

(13) Felicissimo MF, Carneiro MM, Saleme CS, Pinto RZ, da Fonseca AM, da Silva-Filho AL. (2010): Intensive supervised versus unsupervised pelvic floor muscle training for the treatment of stress urinary incontinence: a randomized comparative trial. Int Urogynecol J Pelvic Floor Dysfunct; 21:835-40.

(14) Ferreira C, Barbosa P, Oliveira S, Antônio F, Franco M \& Bø K.;(2011): Inter-rater reliability study of the modified Oxford grading scale and the Peritron manometer. Physiotherapy; 97 (2):132-138.

(15) Fitchett JR, Bhatta S, Sherpa TY, et al, (2015):Non-surgical interventions for pelvic organ prolapse in rural Nepal: a prospective monitoring and evaluation study. JRSM Open. 6(12):2054270415608117.

(16) Frawley ,H., Sherburn, M.,Hagen,S.,\&Galea,M.,(2010): pelvic organ prolapse physiotherapy, Australian and New Zealand Continence Journal Vol.14 No.2

(17) Ghandour L., Minassian V., Al-Badr A., Ghaida R., Geagea S., \& Bazi T. (2016): Prevalence and degree of bother of pelvic floor disorder symptoms among women from primary care and specialty clinics in Lebanon: an exploratory study; 10.1007/s00192-0163080 .

(18) Glazener C, Elders A, MacArthur C, Lancashire R, Herbison R; (2013): Childbirth and prolapse: long-term associations with the symptoms and objective measurement of pelvic organ prolapse, BJOG: An International Journal of Obstetrics \& Gynaecology, $120,2,161$

(19) Hagen S, Stark D. Conservative prevention and management of pelvic organ prolapse in women (2011). [Available from: http://www.ncbi.nlm.nih.gov/pubmed/22161382.

(20) Hagen S, Stark D. (2016). Physiotherapists and prolapse: who's doing what, how and why? Journal of the Association of Chartered Physiotherapists in Women's Health; 103: 5-11.

(21) Harvey, MA. (2015). American College of Obstetrics and Gynecologists, Pelvic floor exercises during and after pregnancy. a systematic review of their role in preventing pelvic floor dysfunction. Journal of Obstetric Gynecological, Canada; 25:487498.

(22) Hassan, M., Osman, N., and Fayez ,T., (2015): Prevalence, risk factors and severity of Symptoms of pelvic organ prolapse among Emirati women, BMC Urology 15:66.

(23) Issacs. and Michael , W.B, (2000) : Hand book in research and evaluation, San Diego, P .225

(24) John, W., \& Sons, L. (2011): Conservative prevention and management of pelvic organ prolapse in women (Review) The Cochrane Collaboration.

(25) Jokhio A, Rizvi R, Rizvi J, MacArthur C , (2013): Urinary Incontinence in Women in rural Pakistan, Prevalence, Severity, Associated factors and Impact on life. BJOG. 120:180-6.

(26) Kudish,B.,Iglesia,C.,Sokol,R.,Cochrane,B.Richter,H.,Larson,J.,(20 13): effect of Weight change on natural history of pelvic organ prolapse, obstetrics and Gynecology; 81-88 available at $\mathrm{http} / /$ www.ncb.nlm.nih.gov/pmc/articles.

(27) Maher, C., Baessler, K., Barber, M., Cheon, C., Deitz ,V. DeTayrac, R.,Gutman, R., Karram, M., Sentilhes, L., (2013) Surgical management of pelvic organ Prolapse, In Abrams, Cardozo, Khoury, Wein (eds), 5th International Consultation on Incontinence. Health Publication Ltd, Paris, Chapter 15 and Modified for publication in International, Urogynaecology Journal.

(28) Mant, J; Painter, R; Vessey, M; (2012): Epidemiology of genital prolapse, observation From the Oxford Family Planning Association Study. Br J Obstet Gynacolo; 104:579. 
(29) Masenga GG, Shayo BC, Rasch V; (2018): Prevalence and risk factors for pelvic organ prolapse in Kilimanjaro, Tanzania: A population based study in Tanzanian rural community. PLoS One. $25,13(4)$.

(30) McClurg, D., Hilton, P., Dolan, L., Monga ,A., Hagen, S., Frawley, H., Dickinson, L., (2014):Pelvic floor muscle training as an adjunct to prolapse surgery, a Randomized feasibility study, Int Urogynecol J. ;25:883-91.

(31) Persu C, Chapple C , Cauni V, et al; (2011); Pelvic Organ Prolapse Quantification System (POP-Q)- a new era in pelvic prolapse staging. J Med Life. 4(1): 75-81.

(32) Priyanka.K, Sukhjit K, Amarjeets S, Neelam A. (2015): A preexperimental study to assess the effectiveness of nursing intervention package on management of pelvic organ prolapse. Nursing and Midwifery Ch Journal, Vol-11, No.3,.P.131.

(33) Priyanka,A.,Kaur,S.,Singh,A.,Aggrawal,N.,(2015):Apreexperimental study to assess The effectiveness of nursing intervention package on management of pelvic organ Prolapse among women, Nursing and Midwifery Research Journal,No.3,pp.131143.
(34) Shrestha B, Choulagai B, Onta S, Shrestha KB, Petzold M, KrettekA. (2014): Knowledge, prevalence and treatment practices of uterine prolapse among women of reproductive age in the Jhaukhel- Duwakot Health Demographic Surveillance Site, Bhaktapur, Nepal. Journal of Kathmandu medical college. 2014;3(4):136-43.

(35) Streicher L. (2013): uterine prolapse and pelvic relaxation. Gynecological specialist of northwestern, \{internet\} \{cited 2013 Dec. 23$\}$ available from: www.mygyne.info/uterine prolapse.htm.

(36) Stüpp, L., Resende , A., Oliveira, E., Castro, R., Girão, M., Sartori, G.,(2011): Pelvic Floor muscle training for treatment of pelvic organ prolapse, an assessor-blinded Randomized controlled trial, Int Urogynecol J , 11 22(10): 1233-9.

(37) Subhagan R. (2010) :Assess Knowledge regarding Prevention of Uterine Prolapse among Postnatal Mothers.Msc thesis, College of nursing, Bengauru.

(38) The Egyptian Journal of Hospital Medicine (July 2017) Vol. 68 (2), Page 1252-1256.

(39) Walker GJA, Gunasekera P, (2011): Pelvic organ prolapse and incontinence in developing countries: review of prevalence and risk factors. Int Urogynecol J.; 22:127-35 